This is an electronic version of an article published in AUSTRALIAN JOURNAL OF PUBLIC ADMINISTRATION (2006), 65, 3, 48-61. AUSTRALIAN JOURNAL OF PUBLIC ADMINISTRATION is available online from http://www.blackwellsynergy.com/loi/ajpa

Article title:

ACCOUNTABILITY VIA PERFORMANCE MEASUREMENT: THE CASE OF CHILD PROTECTION SERVICES

Author name:

Affiliation:

Address:

Word length:
Clare Tilbury

School of Human Services, Griffith University

School of Human Services

Logan campus, Griffith University

University Drive

MEADOWBROOK Q 4131 


\title{
ACCOUNTABILITY VIA PERFORMANCE MEASUREMENT: THE CASE OF CHILD PROTECTION SERVICES
}

\begin{abstract}
Since the 1980s child protection agencies have been subject to enormous scrutiny about perceived poor performance. Concerns are expressed about the capacity of services to cope with demand, the quality of practice, out-of-home care standards, and poor outcomes for children. Enter performance measurement. Using quantitative data to monitor effectiveness and efficiency, performance measurement promises improved resource management and accountability. This article discusses national, Victorian, and Queensland child protection performance measurement regimes. It examines the extent to which performance measurement is used to promote accountability, as well as the indirect role of performance measurement in communicating policy intent. It suggests performance measurement is under-utilised in child protection, but could be enhanced to contribute to better outcomes for children and families.
\end{abstract}




\section{ACCOUNTABILITY VIA PERFORMANCE MEASUREMENT: THE CASE OF CHILD PROTECTION SERVICES}

\section{Introduction}

There has been rapid change in child protection service delivery during the last two decades, partly due to the impact of broader political, social and economic changes, and also to address emerging problems, trends and issues that have arisen within the field. Both in Australia and internationally, there are concerns about the capacity of child protection services to cope with demand; the quality of practice; out-of-home care standards; and poor outcomes for clients, especially for children and young people (Scott 2002; Waldfogel 1998). A widespread perception of poor performance is often fuelled by media coverage that accompanies the public inquiries now commonplace in many jurisdictions, whether child death reviews (Goddard and Saunders 2001) or other inquiries such as the Commission of Inquiry into Abuse of Children in Queensland Institutions (1999) and the Queensland Crime and Misconduct Commission Inquiry into Abuse of Children in Foster Care (2004).

There is pressure to change from two fronts. At the same time as child protection services are grappling with the need to reform emanating from increasing demands and complexity within the field, there have been major changes to the management of public services, including a strong focus on performance. Performance measurement is one of a range of managerial changes introduced to the public sector since the 1980s in the name of improved efficiency and effectiveness. It involves monitoring, 
at a program level, the cost and quality of services and outcomes for clients in order to account for public expenditure (Carter, Klein and Day 1992). Performance measurement promises to deliver accountability and 'hands-off' control in decentralized service delivery systems, a focus on outcomes rather than services, and an objective method of monitoring, assessing, and thereby improving performance (Barratt 1997; Carter, Klein and Day 1992; SCRCSSP 2003).

Australian child protection agencies began developing performance indicators in the 1990s. Unlike in the USA and the UK, there has been little debate here about performance measurement in child protection, but that makes it no less important in terms of its potential impact on policy and practice. This article discusses child protection performance measurement regimes at the national level, in Victoria, and in Queensland. It examines the extent to which performance measurement has been used instrumentally to provide accountability, as well as the indirect, conceptual uses of performance measurement and its role in shaping and communicating policy. An argument is made that the capacity of performance measurement to deliver accountability is enhanced by institutional arrangements whereby both federal and state agencies are reporting publicly on indicators, and by its use in budget processes. However, real accountability in undermined by the reporting data without analysis, the absence of links to performance improvement and specific policy goals, and the narrow range of indicators used. There is a top-down approach, whereby indicators are selected and used by government with minimal debate from other policy actors, and consequently there is little dialogue about what the data 'say' about performance. 
But before turning to the situation in Australia, the article first considers the problems and potential of performance measurement.

\section{Accountability in performance measurement}

Performance measurement is part of a developing audit and measurement culture in government, motivated by concerns about the need for control of public expenditure, managerial competence, and accountability for 'results' (Sanderson 1998). Performance measurement aims to produce not only better information with which to manage, but also to verify 'good' management. It is particularly associated with the rise of the 'accountability movement', involving a shift from narrowly defined 'financial accountability' to a broader notion of 'management accountability' through the use of audit, evaluation, performance appraisal and inspection (Carter, Klein and Day 1992).

In rational-instrumental models, accountability is achieved through procedural or administrative means with a narrow emphasis on accountability upwards to superordinates. But from a critical perspective, accountability involves both political and social obligations. Government has multiple lines of accountability, and accountability has both democratic and control dimensions. This requires a broad notion of accountability: an orientation to democracy rather than to centralized, upwards control (Carter, Klein \& Day 1992; Sanderson 1998). Because performance measurement can provide external as well as internal accountability, it potentially gives a voice to a range of stakeholders. Thus performance indicators can function as 
'tin openers', opening up areas for debate by multiple policy actors, highlighting concerns, prioritising areas for action, and signalling matters for further investigation (Carter, Klein \& Day 1992).

Claims of objectivity in performance measurement are contested in child welfare as in other fields: firstly, the idea that is possible to demonstrate that 'what we do' produces a specific result, when there are so many real-world intervening factors to confound attribution; and secondly the desirability of doing so in quantitative terms, as it reduces a complex reality to something simplistic and one-dimensional (Garrett 1999; Smith 1997). The process of measurement and audit is reliant on guidelines, formalised procedures and standards, which have negative consequences for practice as it focuses on accountability to procedures rather than accountability to clients. This proceduralisation encourages authoritarian practices, de-emphasising the centrality of creativity, judgement and the intangible aspects of services that are difficult to quantify (Parton, Thorpe \& Wattam 1997).

\section{Multiple stakeholders}

A set of child protection performance indicators represents viewpoints about what is important in practice and how best to intervene. Clients, people who report concerns about children, managers at various levels, frontline practitioners, foster carers, politicians, and the general public may all hold different views about the characteristics of effective and efficient services. Even direct clients—children who have been harmed or are at risk and their families—are not a homogeneous group. 
The views of children and young people in care may not be the same as parents' views. Minority racial and ethnic groups, over-represented in child protection systems worldwide, have long called for programs and services to be specifically tailored to recognise their histories, social circumstances and family structures. Their perceptions of an effective child protection system may not accord with those of other client groups.

The multiplicity of legitimate but conflicting perspectives on policy problems gives rise to the argument that claims to neutrality and objectivity in performance measurement have an anti-democratic implication. When performance measurement is top-down and consumer interests are ignored, its orientation is to control rather than democracy (Sanderson 1998). While it may be possible for multiple stakeholders to agree on some outcomes, the ability to select and establish an outcome generally reflects power differentials between stakeholders. Generally, professional definitions of outcomes have taken precedence over client definitions (Stevens 1999).

\section{Theoretical and value perspectives}

Because it involves defining outcomes and objectives, and because it is a tool for budget management, performance measurement can potentially influence how social problems such as child abuse are conceptualised, where resources are placed and what service types are funded (Grasso \& Epstein 1987; Martin \& Kettner 1997). But measuring the effectiveness depends upon assumptions about the objectives of child protection services in any policy regime. For example, the child protection system 
aims to keep vulnerable children safe from abuse and neglect but also has a broader aim of improving their physical, emotional and psychological development. If the dominant policy approach relies upon investigation of maltreatment and placement of children in foster care, then the performance indicators selected to monitor success are likely to be very different to those selected if the dominant approach is assisting families to safely care for their children. The objectives of the child protection system and the problems it seeks to address are by no means clear or uncontested (Gibbons 1997). So divergent views about indicators have a values component, and while the value differences embedded in the selection of indicators can not always be averaged or reconciled, they can be made explicit and discussed (Reid 1987).

Moreover, services are not totally dominated by one theoretical approach and are influenced by changing social circumstances and community expectations. Knowledge in the field has grown rapidly in the last twenty years and modes of service delivery and practice have changed accordingly. Child protection legislation, policy and practice frameworks influence how effectiveness and client outcomes are defined because they define objectives and set standards for how to respond. It follows, therefore, that performance indicators are historically contingent, changing over time to reflect contemporary directions and perceptions of current performance 'problems'. The values dimension makes setting performance indicators more than a technical exercise, as performance regimes should be aligned with broader policy goals. 


\section{Conceptualising outcomes}

Outcomes refer to the consequences or benefits of a service for clients. Client events - changes in client behaviour, knowledge or resources-are preferred to case events or decisions that are agency controlled (such as 'return home', 'case closure') which do not specify what types of client improvements have occurred. That is, it is possible to have programs that meet agency or case goals, but do not meet the needs of clients, or they have longer-term negative side-effects. Courtney (1993) points out both the necessity and the value of child welfare administrators and policy makers developing a greater level of precision about program objectives, making clear and explicit statements about the role and purpose of services and their intended impact on clients.

Because child protection agencies have been subject to criticism about their lack of success in achieving positive change for clients, considerable attention in the literature is directed towards the necessity to measure client outcomes. Safety, permanency and stability, and child and family well-being are the most frequently discussed outcomes (for example, Gain \& Young 1998; Poertner, McDonald \& Murray 2000). A variety of re-abuse, re-registration or recurrence indicators are used to indicate whether the outcome of child safety has been achieved. The rationale for seeking permanent arrangements is that it is not desirable for children to 'drift in care', unsure of who will be looking after them as they grow up (Wise 2000). Placement permanency indicators in the USA and the UK contain restricted timeframes on decision making about return home, after which time parental rights 
may be legally terminated to 'free' the child for adoption. This has proven very controversial. Its evidence base is contested, and there is concern that permanency planning leads to goal displacement: reunification or adoption becomes the focus of intervention, rather than the quality of care the child receives, or less measurable outcomes. (Courtney 1993; Maluccio, Pine \& Warsh 1994). Child well-being is generally defined to include attention to children's health, identity, social presentation, self care skills, education, family and social relationships, and emotional and behavioural development (Parker, Ward, Jackson, Aldgate \& Wedge 1991). Indicators employed to measure these dimensions of child well-being include educational participation and attainment, immunization rates, regularity of health check-ups, and rates of involvement in youth crime.

\section{Effect of measuring on practice}

Choosing items to measure, on the basis that they give an indication of performance, can have both positive and negative influences on practice. A negative influence might be where an organisation allocates resources and concentrates effort on performing well on narrow criteria (Duncan 1995; Grasso \& Epstein 1987). For example, importance might be attached to completing assessments within a preferred timeframe, rather than on the comprehensiveness, sensitivity and quality of assessments (Munro 2000). According to Jacobs and Manzi (2000, p.90), 'performance indicators have played a key role in establishing a culture of measurement in the public sector'. They suggest that this decreases the autonomy, skills and creativity of frontline workers through bureaucratisation and 
proceduralisation of complex tasks to make them measurable (see also Harris 1998; Munro 2000; Parton, Thorpe \& Wattam 1997). On the other hand, collecting performance data on educational attainment is seen to have a positive influence by concentrating the attention of practitioners and policy makers on this sometimes neglected issue for children in care (Goddard 2000).

\section{Benchmarks and targets}

Benchmarks establish a quantifiable level of performance to be achieved. They are relevant to how results are interpreted and compared, because they assist in determining whether the data indicate 'good' or 'bad' performance. Benchmarks can track changes over time or changes compared to an established standard or target (Parker, Ward, Jackson, Aldgate \& Wedge 1991). Of course, there are problems with benchmarks. Where performance is consistently poor over time, a historical benchmark may not assist in performance improvement (Poertner, McDonald \& Murray 2000). Benchmarking across jurisdictions encounters the problem of interpreting the legislative and policy differences that impact on measurability. In Australia, a study to explore the comparability of State and Territory child protection data found that significant and fundamental differences existed in concepts and definitions such as 'notification', 'substantiation' and 'protection order' (Australian Institute of Health and Welfare 1999). There are also differences in client characteristics, the socio-economic composition of the local population, and the availability of related human services for which adjustments are required. On the other hand, cross-jurisdiction benchmarking can challenge existing agency processes. 
For example, Barth and Needell (1997) argue that state and county comparisons in the USA, adjusted for size, helped to stimulate policy and program changes in a way that internal comparisons could not.

However, when indicators are used as 'dials' in which performance is absolute and a target is either achieved or not achieved, real discussion about performance improvement may be suppressed. For example, an unsatisfactory placement may be prolonged to reach a placement stability target, rather than remedying placement quality (Ward \& Skuse 2001). Benchmarks have been accused of contributing to 'gaming' in which activities are manipulated to achieve targets at the expense of more

genuine and sustained performance improvement (Humphrey 2003; Sanderson 1998).

That is, benchmarking may entrench a measurement culture and locate 'poor performers', but rather than promoting open discussion of strategies to improve performance, solutions are automatically located within a management, control framework.

\section{Child protection performance measurement arrangements}

In Australia, the responsibility for child protection is held by State and Territory governments, which each have different legislation, organisational structures and service delivery systems. Nevertheless, arrangements for performance measurement are similar across jurisdictions, as summarised in Table 1.

INSERT TABLE 1 ABOUT HERE 
A set of child protection indicators agreed to by all State and Territory governments has been voluntarily reported on since 1997 through the Steering Committee for the Review of Commonwealth/State Service Provision (SCRCSSP). The SCRCSSP was established in 1994 under the aegis of the Productivity Commission, a federal agency with a microeconomic reform agenda. The SCRCSSP uses a generic indicator framework for all government services, in which there are two dimensions of performance: efficiency and effectiveness. Efficiency is defined as inputs per output unit. Effectiveness is defined as a combination of quality, appropriateness or targeting, access and equity, and achievement of client outcomes.

Performance against fourteen child protection indicators was reported in 2002-03. There is an emphasis on comparative reporting, ostensibly so jurisdictions can learn about better and more cost effective ways to use existing resources, and to generate incentives for agencies to address sub-standard performance (SCRCSSP 2003: 1.31.4). The national indicators are determined by jurisdictions through a representative working party, the National Child Protection and Support Services (NCPASS) Data Group, which is responsible for providing advice on indicators and counting rules. The membership of NCPASS comprises departmental officers representing child protection departments in each State and Territory plus the Australian Institute of Health and Welfare. NCPASS ultimately reports to the Community Services Ministerial Advisory Council. 
Performance measurement relies on the routine collection of data. National collection and reporting of child protection data commenced in Australia in the late 1980s. The Australian Institute of Health and Welfare publishes data relating to reports of child abuse and neglect, children subject to protection orders, and children in out-of-home care (Johnstone 2000). These data form the basis of the national performance reports published by the SCRCSSP. The national data collection does not cover other aspects of child protection work such as support work with families to maintain a child safely at home, or work with young people making the transition from care to independent living. This has implications for the establishment of indicators in a range of areas because not counting an activity or process makes it invisible in performance assessment, even though it might be important to achieving good outcomes. For example, research shows that the regularity and quality of family contact is vital to the prospects for the safe return home of a child, but this activity is not currently counted in the national data collection.

At the State level, output-based budgeting has provided the main impetus for performance measurement. Output-based budgeting purports to shift the focus of public administration away from budget allocations and spending to outputs and outcomes, and relies upon the separation of government's purchaser and provider roles. In the 1990s most Australian state treasury departments introduced outputbased budgeting, in which agencies are funded on the basis of the delivery of services costed on an accrual basis. This contrasts with traditional cash budgets that focus on inputs and services (Guthrie 1998). The budget indicators are determined by the 
Minister and chief executive of the line department and are intended to demonstrate to Parliament and to the community their performance in providing the output. The shift to output budgets brought changes in the presentation of annual budget papers, so that as well as providing textual information about past and planned activities and strategies, line departments also publish quantitative data on outputs and performance.

The cases of Victoria and Queensland are interesting because they have both been active participants in NCPASS since its inception, but they employ different approaches to the provision of child protection services. In Victoria there is a strong policy focus on preventative, community-based approaches and contemporary data spanning both child protection and family support are available. Many services are delivered by the non-government sector. In Queensland there is a legislative focus on family support but more recent attention has concentrated resources on investigation and placement. There is a mixed economy of provision, but the non-government sector is much smaller, and there is no aggregated data collection from these services.

Victoria commenced output-based budgeting in 1996 (Guthrie 1998). One of the aims was to improve the quality of performance information available: 'Managing by outputs ... is designed to improve accountability and performance measurement by focusing on results for customers' (Department of Treasury and Finance Victoria 1996: 4). Output performance is measured in terms of quantity, quality, timeliness and cost, and the measures are used as the basis for setting targets. In 2002-03 there 
were nine performance indicators for child protection-related services in Victoria (Department of Treasury and Finance Victoria 2002).

In Queensland performance indicators have been used in state budget papers since 1999 when the change was made from historical or input-based funding to outputbased budgeting. 'The effectiveness of the purchased outputs in achieving the Government's desired outcomes and the quality and efficiency of the delivery of the outputs will be assessed an ongoing basis through the collection and analysis of performance information. The findings of this analysis will inform the Government's future purchasing decisions’ (Queensland Treasury 1997: 6). Note the emphasis is on informing decision-making within government about matching outputs to outcomes, rather than information for the community. There were seven child protection-related performance indicators reported in 2002-2003 budget papers (Queensland Government 2002). Again, output performance is measured in terms of quantity, quality, timeliness and cost, and targets are set.

Performance measurement is increasingly used as a mechanism for accountability for child protection services purchased by government from non-government organisations. In Victoria, the non-government sector has historically had a significant role in child protection service delivery. The service agreement is the mechanism used to document the services provided by the agency for the funds granted, and to monitor agency performance (Department of Human Services 2003a). Indicators are determined by the Department for each funding program. For example, 
there are performance indicators for 'child protection and placement' services and 'family and community support' services. Data for these indicators are not published in a way that enables performance to be compared between funded agencies. However, some indicators for the funded activities are repeated in the budget set, enabling performance against at least a few indicators to be monitored across funding programs. For example, the 'daily average number of clients receiving a specialist support service' is an indicator in the budget set which also used for funded intensive treatment services and placement prevention services (Department of Treasury and Finance Victoria 2002).

In Queensland, performance indicators are nominally used to manage the funding relationship with non-government agencies, however they are negotiated on an agency-by-agency basis, which limits their usefulness as a program management tool. Outcomes are set for each funding program, but there may be different performance indicators for each service or agency, of which there are hundreds across the state (Families, Youth and Community Care Queensland 2000). Consequently there are no routine or aggregate performance data that enable the government to monitor service delivery that is purchased from non-government agencies, either comparative agency performance or the overall impact of the funding program in terms of whether it has met its objectives or improved child or family welfare.

Performance measurement may also be used for internal reporting within departments, or to monitor progress of policy or program initiatives in documents 
such as strategic plans or policy statements. However, these indicators are not generally publicly reported upon. For example, in strategic plans issued from time-totime the Queensland department has established outcome statements with an accompanying suite of performance indicators. But data for most of the indicators is not collected and performance is not publicly reported with reference to the indicators, so they are marginal to routine, ongoing performance measurement. Recently the Department of Child Safety in Queensland produced Child Protection Queensland: 2004 Child Protection System Baseline Performance Report (Department of Child Safety 2004). It aims to provide an overview of the Government's progress in improving the child protection service system, establishing ‘a baseline against which to compare future performance’. It is intended that reports will be produced annually. If so, they will provide another potential site for performance measurement to improve accountability.

In Victoria and Queensland, as well as nationally, performance measurement regimes are completely developed by government, with limited commentary from other stakeholders such as clients, frontline practitioners, academics or non-government service providers. In recent years performance measures have attracted occasional media attention, generally following the release of the annual SCRCSSP report. For example, 'Child abuse agency fails to protect' (Courier Mail 7 February 2003: 2) and 'Children on foster care roundabout' (Herald Sun Melbourne 11 February 2002: 13). An appraisal of the performance of all State and Territory child protection systems was undertaken in 2000 by an organisation representing young people in care, mainly 
using data from the SCRCSSP reports (Create Foundation 2001). This 'report card' aimed to inform the community and government about how well children are protected and cared for against thirteen indicators or safety and well-being. It signalled that children and young people in care have an interest and a stake in performance measurement. This publication, and subsequent similar ones, has also received media attention. For example, 'Schools fail to educate kids in care' (Courier Mail 28 August 2002: 5). However, academic analyses of either policy or technical issues in relation to performance measurement in this field is scant.

\section{Discussion}

The previous discussion has outlined who is measuring performance, the processes by which performance indicators are selected and used, and the purposes of performance measurement. But to what extent is performance measurement providing accountability? It seems there is plenty of indicator setting and data collection, but little analysis of what the data mean for policy and practice. For example, while data are reported for the national and budget indicator regimes, they are not accompanied by any interpretation of whether the data indicate good or substandard performance. Text adjoining data is descriptive rather than analytical. This makes it very difficult for stakeholders, without an intricate knowledge of the child protection system or the data collection, to know whether the expected results have been achieved, or if not, why not. The interpretation of data is not easy. Understanding what the data 'say' or do not say about child protection requires a level of familiarity both with statistical concepts and with the knowledge base that provides the rationale for the selection of 
the indicator. This issue has been acknowledged at the national level with the publication of guidelines for the interpretation of child protection performance indicators (AIHW 2002), which address the complexities of interpreting the data. However, this is not the same as providing an appraisal (implying some form of judgement) of each jurisdiction's performance on an annual basis, which other stakeholders might accept or contest.

Despite Victoria and Queensland setting targets in budget papers, there is no direct use of targets by either jurisdiction, in as much as there are no consequences for not reaching targets, or even any explanation if expected targets are not achieved. This contrasts with the situation for child protection services in the UK where there are both positive and negative consequences for performance levels achieved. There are financial incentives for local authority social services that do well ${ }^{1}$ (Rushton \& Dance 2002) and on the other hand, poor performance in relation to targets can precipitate intervention by central government: a surveillance, control, and sanction model of accountability (Sanderson 1998). Certainly, proper analyses of performance are not served by simplistic determinations of 'good performance' or 'bad performance' in relation to indicators, and indicators are generally not able to explain the reasons underlying good or poor performance (Ward and Skuse 2001). However,

\footnotetext{
${ }^{1}$ Interestingly two public inquiries that identified significant and systemic problems in child protection services in Queensland attributed these, at least in part, to low levels of funding (Commission of Inquiry into Abuse of Children in Queensland Institutions 1999, recommendation 4; Crime and Misconduct Commission Queensland 2004, recommendations 5.1 and 5.16). Thus 'poor performance' resulted in funding increases, although this was not based on any explicit use of performance indicators or quantitative data analysis.
} 
there seems little point in setting targets without accounting for failure to reach a target or seeking to remedy the situation.

Contemporary data are available for most indicators, especially at national and budget levels. This increases the possibility that they can be used for management purposes, although this has apparently not occurred. Performance measurement has been used mostly internally within government as another form of information for policy deliberations, as an 'input to policy negotiations' (Monro 2003). The purpose of performance measurement appears to be the generalised notion of accountability as the provision of information from providers to purchasers: either line departments to executive government or funded agencies to departments. Performance information is available to external stakeholders about government services via the Report on Government Services, budget papers and annual reports. However, these reports are not pitched towards the general public as an audience. Performance measurement has a passive informational role, implying a descriptive, rather than prescriptive, use of indicators (Carter, Klein \& Day 1992).

The SCRCSSP suggests that comparative performance reporting across jurisdictions provides incentives for poor-performing jurisdictions to improve (perhaps a muted version of the 'naming and shaming' that occurs in the UK). However, it is difficult to envisage how this could occur without providing any analysis of what the data reported by jurisdictions actually means, or use of benchmarks. A survey of readers of the SCRCSSP reports conducted in 1998 found that the reports were used within 
government for strategic budget and policy planning, policy evaluation, assessing resource needs and assessing performance. Central agency users found the reports more 'useful' than line department users (Secretariat for the Review of Commonwealth/State Service Provision 1998). This confirms the view that line departments do not use the data to assess their own performance. However, absent of detailed understanding how the child protection system operates, it would be very difficult for central agencies to correctly interpret data, much less make comparisons with other jurisdictions across largely incompatible data (Australian Institute of Health and Welfare 1999). That benchmarking with other jurisdictions is seriously hampered by data incompatibility is acknowledged, but this does not explain why historical benchmarks are not used to encourage performance improvement over time.

Moreover, the focus of indicators is on outputs and processes rather than outcomes. There are few, if any, explicit links between the performance measurement regime and specific government objectives, much less outcomes for the users of child protection services. The only client outcome indicators used by Victoria and Queensland relate to re-abuse rates: the extent to which the agency is successful in preventing further abuse to a child who has been assessed as having been harmed or being at risk of harm. This is a very narrow construction of 'good outcomes' for a maltreated child. For example, there are no indicators for monitoring whether child protection intervention has succeeded in meeting a child's broader social, health, educational or emotional needs. There are no client satisfaction indicators. 
There is virtually no reporting of data from funded agencies, so it seems unlikely that data from agencies is used for performance monitoring. As there is no aggregation of these performance data there is no capacity to assess whether a funding program has achieved its objectives. Therefore performance data does not appear to inform government purchasing decisions at the departmental level, despite the fact that a significant proportion of child protection expenditure is allocated to non-government agencies. [It is not possible to calculate from published documents the exact percentages specifically for child protection, but in 2002-03 in Victoria, 70 per cent of total community care programs in financial terms were delivered by nongovernment organisations and local government (Department of Human Services 2003b), and in Queensland in that year 36 per cent of the budget for services to children, families and communities and youth justice was allocated to nongovernment organisations (Department of Families 2003)]. If the data are not used to monitor or assess performance, they cannot deliver accountability or control, and again it follows that there is no link to performance improvement.

The development and reporting of performance indicators could be regarded as an opportunity to increase public, political and professional awareness as to the effectiveness of child protection intervention and to explore ways to build better responses. The existence of data can open appraisals of performance to interpretation by other policy actors. An example of this is where data were used by Create (discussed earlier) to assess performance from the point of view of a child in care. In this way, performance measurement enhances public accountability by (at least) 
providing data that are available for scrutiny. A 'stakeholding democracy' is promoted through the inclusion of client, carer and frontline staff views in performance assessments (Humphrey 2003). The point of using performance indicators should not be to make definitive judgments about performance but to facilitate an open and reflective approach, bringing more clarity to how problems are understood and therefore where to look for solutions. This requires a climate of openness. Current media reporting of child protection performance data tends to be negative, so as a form of audit performance measurement provides more 'criticism' than 'comfort' (Power 1997). This has implications for the extent to which performance measurement can open up debate, as negative performance assessments may provoke defensive organisational responses. For example, Munro (2004) suggests the media spotlight on poor child protection performers in the UK has led to defensive blame-shifting reactions, suppressing rather than promoting critical reflection.

It is apparent that performance measurement is not being used to full effect to promote accountability. There is a dearth of performance data about some key aspects of service delivery and from non-government providers-the indicator regimes lack comprehensiveness. There is insufficient interpretation of the data that are available, leading to reporting of performance data rather than of performance assessments—an inadequate conversion of data to information. When targets are established they are not linked to any performance improvement strategies. The linkages between inputs, processes, outputs and outcomes are not well established, making the performance 
indicator regimes divorced from other policy processes. Finally, performance measurement is largely a government controlled, top-down process in which there is limited participation by other policy actors.

There is scope for improving the instrumental applications of performance measurement to achieve accountability. For example, jurisdictional performance could be assessed year-on-year; explanations of performance levels could be provided with linkages to improvement plans; and bonuses or incentives could be offered to reward performance improvement. Importantly, performance measurement could be more integrated with policy, with indicators linked to specific policy objectives, comprehensively covering all aspects of service delivery, balancing efficiency and effectiveness, linking to clear outcome statements that translate to appropriate levels of service delivery. In this way, indicators would support policy rather than function as an 'add on', tangential to real performance improvement.

Despite its limited instrumental uses for accountability purposes in the two jurisdictions discussed in this article, performance measurement may still be used indirectly and conceptually. Performance measurement is generally depicted as a neutral, technical exercise that provides objective data for decision-making. But indicators are not value-free; they represent viewpoints on good performance. Thus performance measurement has political as well as technical dimensions: it communicates policy intent, shaping the way we think and talk about child protection, defining and redefining notions of outcomes, effectiveness and quality. It 
is capable of directing policy attention and resources to elements of 'good' practice and ignoring other aspects of practice.

So at this discursive level, how does performance measurement operate in the policy process? On the whole, performance measurement has concentrated attention on the 'child rescue' construction of child protection. That is, it conceptualizes child protection fundamentally as investigation and placement, a model that reinforces personal pathology versus structural accounts of the causes of abuse and neglect (Whittaker 1991). Mirroring international trends, in the 1990s most Australian child protection jurisdictions, (including Victoria and Queensland) sought to move away from the child rescue paradigm towards a 'new' model of child protection and family support, which seeks to address the problems that arise from concentrating resources on investigation and surveillance at the expense of helping families to address their problems (Tomison 2001). This locates statutory child protection services for maltreated or at-risk children as one part of a broader system of child and family welfare (Department of Human Services 2000; Crime and Misconduct Commission Queensland 2004). Yet the vast majority of indicators relate to the effectiveness and efficiency of investigations and placements. While Victoria has established performance indicators for contracted family support services, these are not reported. Queensland's performance regime ignores work undertaken with families to maintain children safely at home, and the absence of a family support data collection impedes performance assessment in this area. Thus, we can take for granted that investigation and out-of-home care are essential to protecting at-risk children while the inclusion of 
family support has to be justified. The underlying values of the indicators promote the perspective that 'good practice' in child protection is mainly about achieving safety and placement stability for children.

The selection of indicators focuses policy action (at least in part) on the topics the data represent. For example, safety becomes the absence of re-abuse, quality is defined as placement stability, placement stability relates to the number of placement moves or the length of time in placement, and well-being is measured (if at all) only for children in out-of-home care. This ignores the broader role of child protection services, not just keeping children safe from further abuse or neglect, but also promoting their well-being and ensuring that their life chances are improved following intervention (whether the child stays at home or is placed in out-of-home care). Therefore there is a disjuncture between the goals expressed in legislation and policy documents and the goals communicated through performance measurement, or between 'professional' and 'management' concerns.

\section{Conclusion}

Given the orthodoxy of managerialism in the public sector, it is surprising how little performance measurement is actually occurring in Australian child protection agencies. But it is likely that performance measurement will continue to develop. The processes for developing and reporting on the indicators are institutionalized, involving relationships between several different arms of government, and between government and non-government agencies. Within the State, Treasury and executive 
government require performance data to be produced and reported. Within the Commonwealth, the SCRCSSP arrangements, albeit voluntary, place pressure on jurisdictions to participate in performance measurement in the interests of transparency. In the two State jurisdictions discussed here, performance measurement so far has been more oriented to the provision of information than towards accountability for achieving performance goals.

Performance measurement raises many questions about the information that can and should be used to examine issues such as the effectiveness of services in protecting children and helping their families, how resources are allocated, and the quality and standard of services provided to clients. There are competing views about the objectives of child protection services held by multiple and diverse stakeholders; there are problems with establishing causal links between inputs, outputs, processes and outcomes; reductionist and inappropriate inferences may be drawn from data; there are tensions in balancing effectiveness and efficiency; and concerns about whether caring can be quantified (Carter, Klein and Day 1992; Everitt and Hardiker 1996; Nocon and Qureshi 1996; Ward and Skuse 2001). Performance measurement has also been implicated in attempts to exert control over frontline social work practice, shifting practitioner focus from professional and client interests to organisational demands (Harris 1998). However, performance measurement is a feature of the contemporary government landscape and it is in the interests of child protection services to orient it towards the elements of practice consistent with good outcomes for children and young people. 
This article argues that how we measure child protection makes a difference to how we think about its problems and solutions, and that the selection and use of indicators is integral to policy processes. Performance indicators do not just retrospectively monitor policy implementation; they also constitute policy. This makes the institutionalisation of indicators a 'double edged sword' (Innes 1990: 232) because it is possible for unsatisfactory concepts to become permanent and begin to confine thinking about the nature of problems and putting boundaries around solutions. This reinforces the importance of enhancing the cross-fertilisation of ideas between the worlds of research, child protection policy and practice and the world of performance measurement. Child protection is prone to policy shifts based more on ideology than empirical evidence (Waldfogel 1998), and in this context, performance data provides a level of reliability about trends and issues. However, the 'knowledge' that performance indicators produce is made more meaningful through critical scrutiny of its processes and products. Unless performance measurement is oriented towards the production of meaningful knowledge that opens up debate, it will be tangential to real improvements in outcomes for the children and families who are the clients of child protection services. Reporting numbers without analysis does not engage with questions of effectiveness, build knowledge and understanding, or assist with reflection and critique. Performance measurement that is undertaken as a 'ritual of verification' undermines the potential role of indicators as a basis for public dialogue (Power 1997). It can close off debate rather than open it up, providing a narrow form of accountability from one organizational level to the next, resisting or impeding 
broader accountability from government to citizens. In the interests of outwardlooking child protection services that are truly accountable, open to revitalisation and positive change, it is important that such limited forms of performance measurement are resisted. 


\section{References}

Australian Institute of Health and Welfare 1999 Comparability of child protection data, Australian Institute of Health and Welfare, Canberra.

Australian Institute of Health and Welfare 2002 Guidelines for Interpretation of Child Protection and Out-of-Home Care Performance Indicators, Australian Institute of Health and Welfare, Canberra.

Barratt, P 1997 'Performance standards and evaluation', Australian Journal of Public Administration 56(3): 96-105.

Barth, RP \& Needell, B 1997 Using performance indicators with child welfare policy makers and managers, Evaluating State Policy: the effective use of administrative data, Joint Centre for Poverty Research, Illinois.

Carter, N, R Klein \& P Day 1992 How Organisations Measure Success: The Use of Performance Indicators in Government, Routledge, London.

Cheetham J, R Fuller, G McIvor \& A Petch 1992 Evaluating Social Work Effectiveness, Open University Press, Buckingham.

Commission of Inquiry into Abuse of Children in Queensland Institutions 1999 Report of the Commission of Inquiry into Abuse of Children in Queensland Institutions, Queensland Government, Brisbane.

Create Foundation 2001 Australian Children and Young People in Care: Education Report Card, Create Foundation, n.p.

Crime and Misconduct Commission Queensland 2004 Protecting children: an inquiry into abuse of children in foster care, CMC, Brisbane. 
Courtney, M 1993 'Standardised outcome evaluation of child welfare services out-ofhome care: problems and possibilities', Children and Youth Services Review 15(5): 349-369.

Department of Families 2003 2002-2003 Annual Report, Department of Families, Brisbane.

Department of Human Services 2000 Stronger Citizens, Stronger Families, Stronger Communities: Partnerships in Community Care, DHS Community Care Division, Melbourne.

Department of Human Services 2003a The Community Care Policy and Funding Plan 2003-2006, DHS Community Care Division, Melbourne.

Department of Human Services 2003b 2002-2003 Annual Report, DHS, Melbourne. Department of Treasury and Finance Victoria 1996 A Guide to Output Specification and Performance Measurement, Department of Treasury and Finance Victoria, Melbourne.

Department of Treasury and Finance Victoria 2002 Budget Paper no. 3, Budget Estimates 2002-03, Human Services, Victorian Government, Melbourne.

Duncan, G 1995 ‘New Mandarins New Zealand style’ in The Human Costs of Managerialism, S Rees \& G Rodley, Pluto, Sydney.

Everitt, A \& P Hardiker 1996 Evaluating for Good Practice, Macmillan, London.

Families, Youth and Community Care Queensland 2000 Community Services Funding Book. Families, Youth and Community Care Queensland, Brisbane.

Gain, L \& L Young 1998 Outcome measurement in child protection: International literature review and critical analysis of child protection and alternative 
placement outcome measures, Steering Committee for the Review of Commonwealth/State Service Provision, Melbourne.

Garrett, PM 1999 'Mapping child-care social work in the final years of the twentieth century: a critical response to the Looking After Children system', British Journal of Social Work 29(1): 27-47.

Gibbons, J 1997 'Relating outcomes to objectives in child protection policy’ in Child Protection and Family Support, N Parton, Routledge, London: 78-91.

Goddard, CR \& B Saunders 2001 'Child abuse and the media', National Child Protection Clearinghouse Issues Paper 14: 1-22.

Goddard, J 2000 'The education of looked after children', Child and Family Social Work 5: 79-86.

Grasso, AJ. \& I Epstein 1987 'Management by measurement: organizational opportunities and dilemmas' Administration in Social Work 11(3/4): 89-100.

Guthrie J 1998 Australian experiences of output based budgeting: a critical reflection, Australasian Evaluation Society 1998 International Conference, Melbourne.

Harris J 1998 ‘Scientific management, bureau-professionalism, new managerialism: The labour process of state social work', British Journal of Social Work 28(6): 839-862.

Human Rights and Equal Opportunity Commission 1997 Bringing them home: report of the National Inquiry into the Separation of Aboriginal and Torres Strait Islander Children from their Families, HREOC, Sydney. 
Humphrey JC 2003 'Joint Reviews: Judgment Day and Beyond', British Journal of Social Work 33(6): 727-738.

Innes JE 1990 Knowledge and Public Policy, Transaction Publishers, New Brunswick USA.

Jacobs K \& T Manzi 2000 'Performance indicators and social constructionism: conflict and control in housing management', Critical Social Policy 20(1): 85103.

Johnstone H 2000 The national child protection data collection - what does ten years worth of data tell us? 7th Australian Institute of Family Studies Conference, Sydney.

Maluccio, A, E Fein \& I Davis 1994 'Family reunification: Research findings, issues and directions', Child Welfare 73(5): 489-504.

Martin, LL. \& PM Kettner 1997 'Performance measurement: the new accountability', Administration in Social Work 21(1): 17-29.

Monro, D 2003 'The role of performance measures in a Federal-state context: the examples of housing and disability services', Australian Journal of Public Administration 62(1): 70-79.

Munro, E 2000 'Defending professional social work practice’ in Reclaiming Social Work: The Southport Papers, J. Harris, L. Froggett \& I. Paylor. London, Venture Press, 1:1-10.

Munro, E 2004 'The Impact of Audit on Social Work Practice', British Journal of Social Work 34(8): 1075-1095. 
Nocon, A \& H Qureshi 1996 Outcomes of Community Care for Users and Carers, Open University Press, Buckingham, UK.

Parker, R, H Ward, S Jackson, J Aldgate \& P Wedge (Eds) 1991 Looking After Children: Assessing Outcomes in Child Care, HMSO, London.

Parton, N, D Thorpe \& C Wattam 1997 Child Protection: Risk and the Moral Order, Macmillan, Basingstoke UK.

Poertner, J, TP. McDonald \& C Murray 2000 'Child welfare outcomes revisited', Children and Youth Services Review 22(9/10): 789-810.

Power, M 1997 The Audit Society: Rituals of Verification, Oxford University Press, Oxford.

Queensland Government 2002 Ministerial Portfolio Statements, 2002-03 State Budget, Minister for Families and Minister for Aboriginal and Torres Strait Islander Policy and Minister for Disability Services, Queensland Government, Brisbane.

Queensland Treasury 1997 Managing for Outcomes in Queensland, Queensland Treasury, Brisbane.

Reid, WJ 1987 'Service effectiveness and the social agency', Administration in Social Work 11(3/4): 41-58.

Rushton, A \& C Dance 2002 'Quality Protects: A commentary on the Government's agenda and the evidence base', Child and Adolescent Mental Health 7(2): 6065.

Sanderson, I 1998 'Beyond performance measurement? Assessing 'value' in local government', Local Government Studies 24(4): 1-25. 
Scott, D 2002 'Child protection service system reform: a way forward', Children Australia 27(1): 42-44.

SCRCSSP - see Steering Committee for the Review of Commonwealth/State Service Provision

Secretariat for the Review of Commonwealth/State Service Provision 1998 Feedback on the Report on Government Services, Ausinfo, Canberra.

Smith, C 1997 'Children's rights: have carers abandoned values?', Children and Society 11: 3-15.

Steering Committee for the Review of Commonwealth/State Service Provision 2003 Report on Government Services 2003, Productivity Commission, Canberra.

Stevens, M. 1999 'Assessing outcomes in child welfare: a critical review', Research Policy and Planning 17(1): 26-32.

Tomison, A 2001 'A history of child protection: back to the future', Family Matters 60: 46-57.

Waldfogel, J 1998 The Future of Child Protection, Harvard University Press, Cambridge, Mass.

Ward, H \& T Skuse 2001 'Performance targets and stability of placements for children looked after away from home’, Children and Society 15: 333-346.

Whittaker, JK 1991 'The leadership challenge in family-based services: policy, practice and research', Families in Society 72(5): 294-300.

Wise, S 2000 'Permanent family placement for children unable to live with their birth families: challenges and controversies', Children Australia 25(4): 4-6. 


\section{Table 1: Performance measurement arrangements in Australia}

\begin{tabular}{l|l} 
National indicators & State Budget indicators
\end{tabular}

Established by agreement by States and

Territories. Data published by the Steering

Committee for the Review of

Commonwealth /State Service Provision in

the annual Report on Government Services.

Indicators for funded services

Established by line departments to monitor

performance of services provided by funded agencies in the non-government sector.

Generally data are not published.

Established by line departments for reporting to Treasury. Data published in annual budget papers and usually also published in departmental Annual Reports.

\section{Departmental indicators}

Line departments may establish indicators to monitor performance of internal workgroups or to monitor progress of specific policy or sub-program initiatives. Data are not published. 